\title{
An Administration of the New Electronic Identity Management System in Southwestern Nigeria
}

\author{
Oluwadare Ayeni ${ }^{1}$ \\ ${ }^{1}$ Department of Public Administration, Obafemi Awolowo University, Ile-Ife, Nigeria \\ Correspondence: Oluwadare Ayeni, Department of Public Administration, Obafemi Awolowo University, Ile-Ife, \\ Nigeria. E-mail: 234-80-7450-0000; 234-81-4441-1777. E-mail: oluwadareayeni.oauife@gmail.com; \\ ooayen@oauife.edu.ng
}

Received: August 19, 2019 Accepted: September 18, 2019 Online Published: April 29, 2020

doi:10.5539/par.v9n1p30

URL: http://dx.doi.org/10.5539/par.v9n1p30

\begin{abstract}
The implementation phase of any policy either at the global, national, regional or organizational level has one important driving force, the policy strategies. They serve as the mapping hedge for controlling potential deviation or shortfall from the policy targets using the policy outcomes as the checker. Drawing its strength from a wide gap between the targets and outcomes of the National Policy on Identification System in Nigeria, this paper examines the policy strategies employed by the relevant agency for the ongoing implementation of the new Identification System using a qualitative and quantitative method. 31 staff of the National Identity Management Commission (NIMC) representing 10\% of the study population (311) was administered with a closed-ended questionnaire, and in-depth interview conducted among some senior officers of the Commission. Percentages and narrative analysis were used to analyse the data. Findings showed that deployment of a user-friendly pre-enrollment electronic interface (57.1\%); deployment of national ICT infrastructure $(57.1 \%)$; inter-agencies collaboration (50\%) were the only effective strategies among those identified by the study. The study submitted that most of the existing implementation strategies employed for the new Identification Policy in Nigeria are not effective. It further recommended among others decentralization of the enrollment process as well as an effective deployment of mobile registration centers to fast-track attainment of the targets set out in policy under review.
\end{abstract}

Keywords: implementation, strategies, identification, policy, identity management system

\section{Introduction}

The introduction of internet-based resources called World Wide Web (WWW) into information technology in the 1990s opened a new phase of human civilisation as digital pathways were created for internet users to access information on the internet (Organisation for Economic Cooperation Development [OECD], 2011). This discovery allowed for interaction between remote computer systems and individuals especially for delivery of information and services in a bespoke manner. As a result, there is a new wave of enquiry into how the deployment of the internet can be harnessed by government at national and international levels. Government around the globe exploited the surge in information technology in the process of addressing developmental challenges affecting the socio-economic development of their respective countries. One such layer of development is an efficient, robust and effective identity management system.

Identity management is significant in public administration. For instance, certain public services cannot be efficiently rendered by government unless every individual and establishment is uniquely identified. Thus, services such as social security services, health services, revenue collection, election administration, population census among others, cannot be successfully rendered with the dearth of a working identity management system. In appreciation of this, government at national and cross-national levels are directing efforts in designing and installing an identification system that would provide a generally accepted platform for verifying and validating the identity of individuals, especially when accessing public services. For instance, Anderson et al. (2016) reported that identification systems are becoming prevalent across Latin America, Southeast Asia, and Sub-Saharan Africa, claiming that out of 43 identity programmes assessed, 29 have been introduced in the last ten years while 14 of them came in the last five years. This portrays the level of importance attached to the new order of the identification system. 
The trajectory of the national identity management system in Nigeria dated back to the post-independence era (Musa, 2000). For more than four decades, the development of a framework for identity management system has always seamlessly emerged in the government agenda for socio-economic and political development in Nigeria. In 1978, the Directorate of National Civic Registration (DNCR) was established (Ayamba and Ekanem, 2016). This was later backed by decree 51 of 1979. The DNCR was responsible for the enrollment of citizens from 18 years above for National Identity Card (Vanguard May 13, 2003). The government intended to establish a national identity management system to resolve the challenges of verifying and authenticating the true identity of individuals when accessing public service deliverables (NIMC, 2013).

Consequently, a series of government programmes aimed at installing a reliable identification system has always witnessed drawbacks of varying magnitude. Among these drawbacks are fragmented system, multiple forms of ID cards, non-existence of interoperability, low coverage and absence of common standards as part of the blight that confronted previous identification schemes (Aliyu, 2017). As a result of these ignoble realities,

"the government commissioned a Harmonisation Committee to advise it on how different public and private sector activities on identification systems can be harmonised, therefore, the committee recommended a National Policy and Institutional Framework for a National Identity Management System for the country" (Ayamba \& Ekanem, 2016, p.280).

The national policy and institutional framework for an identity management system for Nigeria deployed in 2007 with the overriding policy thrust to harmonise existing identification schemes, introduce a unique national identification scheme, institutionalise a system of identity management, and establish a reliable environment of identity management. All these thrusts are expected to manifest into attainment of a variety of the policy objectives set out in the policy documents especially in the area of interoperability among government agencies. Going by the foregoing, the new identification system in Nigeria is expected to provide a foundational database that can be accessed by government agencies providing e-services. However, available evidence raises concern. For instance, the policy targeted the distribution of at least 12 million NINs to Nigerians in the first year of implementation.

Eventually, World Bank Report on the country assessment of the identification system observed that the first National Identification Number was first issued in 2012, 4 years after commencement of the policy (World Bank, 2015). The report also revealed that only 6.1 millions NINs were issued to Nigerians representing $3.5 \%$ of the total population of Nigeria in 2015. Also, as of September 2017, 21 millions NINs has been issued against an estimated population of over 180 million persons in Nigeria equating $12 \%$ of the population. Also, it is reported that the National Identity Management Commission operates 805 registration centres out of which 556 centres are sited in local governments (NIMC's Official Release, 2017). The implication of this is that 218 local government offices are without enrollment centres, this might lead to the exclusion of a certain number of people from enrollment into the national database. This poses a threat to the policy objective of ensuring interoperability among government institutions as the numbers of identities captured and databases integrated do not guarantee the provision of all-inclusive e-government services. Drawing its gap from the paucity of the extant literature on the effectiveness of the implementation strategies of the national identification policy in Nigeria; hence this paper.

\section{Models of Identity Management System}

Opinions differ on different models of identity management system, but it appears that authors converge on three models of identity management system (Oxford Internet Institute 2006; OECD, 2007; Lips and Pang, 2008; Olaniyi, 2017). These models provide an avenue for one-off sign-on to the users to access a variety of transactions in the public domain, yet each of the models possesses its peculiarities especially in the utilisation of identity-related information. These models include organisation-centric identity management model; a user-centric identity management model; a federated Identity management model.

\section{Organisation-centric Identity Management Model}

This model is centralised and operated on a cross-domain basis. It permits the organisation to house and manages user's personal information. The design's construct allows for the synchronisation of user's identities (OECD, 2007). Here, the algorithm of the arrangement is linked to hierarchical rules (Greenwood, 2007). For Hansen et al (2004), this model is desirable to the commercial community as businesses will approve centrality of identity-related service solutions since it guarantees promptness in the management of their identity and access based issues and demands lesser support from them. Good as the model appears it has its condemnation. Authors have raised reservations especially in the area of over-concentration of individual data in the hands of a single 
entity; the possibility of large-scale errors, exposure of individuals to the risk of data leakage and unwarranted from unknown victimisation.

\section{User-centric Identity Management Model}

This model allows the users' full control over their identity-related information. The activities between several personal data $\log$ can only be conducted by a single user. Though, the model is still undergoing scholarly interrogations. Submissions from several arguments support that the model is developed to protect the interest of the users in terms of ownership of their data and privacy (Lips and Pang, 2008). A user-centric model operates on the following three-legged components: identity providers- allow the creation of a separate account for user's identity-related information; relying on parties- give access to agencies that provide services to authenticate the request from identity providers; identity selector-authorise users to elect any service or identity providers they want.

It is assumed that if this model is implemented in conjunction with organisation-centric model and federated model, more gains are accurate especially in the data-sharing outfit (OII, 2007). However, with this arrangement, users are responsible for privacy-related liability (Hansen et al, 2003).

\section{Federated Identity Management}

The Federated model allows access to codified personal information of users to be granted by the owner (user) of such information. It is structured in a way that accesses to the information by several identity management outfits are determined by the users. The model is trust-driven as users authenticate primary access, then, set up access for public and private service providers to interact with identity providers. The administration of individual identity data in the federated model is anchored on the existing relationship among the parties involved. Federated identity management is designed to define the relationship between independent parties in an identification outfit in a mutually exclusive protocol. Operationally, the ownership and decisions in this model are collective. Though the primary user retains the privacy decision, any other decision and action are guided by collectively determined relational rules and protocol (OECD, 2007). Besides, premises have been offered by scholars to situate the federated model as prime among other models. For instance, Liberty Alliance Project (2004), enumerate benefits of the model to include strong safeguard against management and security risk; cost minimisation and reduction; enhanced inter-agencies collaboration; improved communication and interoperability among government organisations, while the model is questioned for trust issues and duplication of identities.

\section{The Indian Aadhaar Programme: Alternative Benchmarking for Implementation}

According to Asia Development Bank Report (2016), India had issues in managing social safety schemes due to the proliferation of fake beneficiaries and identities; as such a new identity management regime was launched to block these leakages. Today, the Indian Identity Management System is the largest in the world with a unified database repository of 940 million identifies. The deployment and adoption of an identification system in India are unique especially in the rate at which the programme was able to capture a huge number of Indians in less than five years. According to Peshwani and Joshi (2016), the national identification system in Indian would have enrolled more than one billion Indians by 2020. This submission shows that the deployment of identity management though came late but well received by the people in India. The current regime of identity management (popularly called Aadhaar) was launched in 2009 to enroll over 1.2 billion Indians by the end of 2020 (Gerdeman, 2012). This scheme is aimed at deepening e-governance and identity management industry that foster direct payment of benefits by the government to stabilise employment scheme as well as promote financial services and inclusion (Chakrabarty, 2012).

The identity regime also has central surveillance features to protect citizens from terror attacks (Sun, Hichang \& Sarchez, 2009). The pattern of enrollment into the Aadhaar programme in India is self-initiated. This means that citizens who consider the benefits and gains of the card will go for enrollment- it is not mandatory (Ramanathan, 2010; Dreze, 2010). This stand implies that for Aadhaar Card enrollment in India to be almost one billion (Peshawani \& Joshi, 2016), the level of technology acceptance and awareness of the current regime among the Indian population is impressive. The proposed benefits of the Indian Aadhaar card include payment of government subsidies to citizens whose bank accounts are linked with Aadhar number and digital documentation of public documents and citizens' records to promote e-government services (Pati, Kumar and Jain, 2015).

According to the Asian Development Bank, (2016), Identity management system has been utilised in various sectors of the Indian economy. Through the deployment of the Aadhaar project, the government has been able to link Aadhaar identifiers and bank accounts of beneficiaries of the National Rural Employment Guarantee 
Scheme (NREGS) to expedite payment of monthly stipend to citizens who were not banked before (Asian Development Bank, 2016). Still on utilisation and spill-over effects of Aadhaar regime in India, study shows that pilferages and leakages in gas delivery are curtailed as well as strengthened financial inclusion in the remote areas in India (Asian Development Bank, 2016) while transparency, interoperability among government agencies, payment of government benefits, and private sector driven e-transaction has been promoted by the new identity management regime in India.

However, authors have also raised voices about some deficiencies that must be looked into by the government of India. For instance, Rati, Kumar, and Jain (2015) observed that despite massive enrollment, the government plan to integrate the national database reservoir with other government agencies has failed, this is in tally with the submission of Mukherjee and Nayar (2011) that it appears that the attention of the government of India is concentrated only on awareness to enrol while little efforts are made towards utilisation of the system among Indians. Legal and privacy issues also appeared in the literature; the argument is that the arrangement of the Aadhaar Programme possibly jeopardises the right to privacy of the citizens as they are vulnerable to misapplication of identity-related information by compromisable officials. Kaushik (2010) and the Unique Identification Authority of India (2010) noted that the worsening relationship between citizens and government in India is affecting the trust and confidence citizens repose in the Aaadhaar programme due to possible misuse of the personal information of citizens by the government and opportune possessors. In the same path of reasoning, Pati, Kamar, and Rain (2015) hinted that the scope of the programme is threatened by lack of public supports, concerns over privacy and unreliability of fingerprints; deployment of incompetence resources (human and technology); improper monitoring. Perhaps these challenges are overweighed by the long-term benefits of the programme.

The Aadhaar programme from existing literature appears to be successful only in the area of enrollment as much still needs to be done in terms of harmonisation, integration, and utilisation of the identity database in India. For Kant and Sharma (2013), and Pati, Kamar and Rain (2015) identity management system in India requires the cogent attention of the government in the area of personnel training; information security, information sharing, collaboration, and coordination among stakeholders, an awareness campaign on usage and verification platforms.

\section{Methodological Description}

This study carried was out in the southwest geopolitical region in Nigeria. The south-west was selected because it had the highest coverage with 2,473,113 enrollees for the period covered by this study (Technology Times, 2017). This study employed a descriptive research design as its blueprints. The study utilised a survey method to systematically seek data from the respondents using a questionnaire and in-depth interviews as research instruments. The questionnaire and the interview guide was structured in line with the objective of the study with the general aim of assessing the effectiveness of the implementation strategies of national policy on identity management. Quantitative and qualitative data were gathered through primary and secondary sources, and descriptive statistics were used to analyse data. This study population comprised 311 staff at the state offices of the National Identity Management Commission in Southwestern Nigeria: Oyo (122); Ekiti (79) and Ogun (110). The Commission was purposefully selected being the institution at the forefront of the policy implementation. The sample size of the study was 31 representing $10 \%$ of the study population. Questionnaire was used to elicit the perception of participants on the implementation strategies of the national policy on identity management system in Southwestern Nigeria using a Likert scale of 5 dimensions ( 0 - Not Yet, 1 -Less effective, 2 - Fairly Effective, 3 - Effective, 4 - Extremely effective ). The interview guide was administered to the interviewees to further gather information on the strategies adopted for policy implementation. Hence, a deputy coordinator, one facility manager, three (3) enrollment officers from NIMC.

However, the implementation strategies adopted in implementing the national policy on the identification system in the study area. Here, each of the identified policy strategies was subjected to the opinion of the respondents selected from the implementing agency - NIMC to examine the potency or otherwise of each of the identified strategies. Their responses were categorised along with the following measurement scales: Extremely effective (4), Effective (3), Fairly Effective (2), Less Effective (1) and Not Yet (0) in table 1. Table and percentages were used to present and analyse data gathered from them.

\section{Research Results and Discussion}

$60.7 \%$ of the respondents believed that the use of public-private partnerships in providing appropriate technology and e-solutions was less effective. $21.4 \%$ of the respondents said this strategy was fairly effective in the process of implementing the policy under review. $7.1 \%$ and $3.6 \%$ of the responses showed that public-private partnership as a strategy was effective and extremely effective respectively while $7.1 \%$ of the respondents thought that 
adoption of the public-private partnership had no positive addition to the implementation process of the policy. Hence, it was concluded that the adoption of public-private partnership as an implementation strategy has been proved to be a less effective strategy. Harmonisation timeline was tested as a variable. The result indicated that $64.3 \%$ of the sampled staff were of the view that the use of harmonisation timeline proved to be fairly effective in the process of implementing the policy. The remaining percentage was between staff who believed that harmonisation timeline was either effective $(10.7 \%)$ or less effective $(25 \%)$. Therefore, harmonisation timeline was fairly effective as an implementation strategy.

The policy document prescribed deployment of National ICT infrastructure as a key strategy for implementing the policy. However, the results from the survey conducted show that a mere $5 \%$ of the responses indicated that the deployment of ICT infrastructures was only fairly effective in the implementation process. Other responses were rated as follows: extremely effective $(17.9 \%)$, effective $(25 \%)$ and less effective $(7.1 \%)$. The study inferred that the deployment of ICT infrastructure as an implementation strategy has not aided the process of implementing the policy within the period under review. Constant review of the legal framework that supports the identification system in Nigeria was viewed as not effective. This position was corroborated by $64.3 \%$ of the respondents. Table 4.2 shows that $25 \%$ of the responses aired from the staff billed review of the existing legal framework as a fairly effective strategy, $7.1 \%$ of the respondents billed it as a less effective strategy. $3.6 \%$ of the staff suggested it as an effective strategy. These figures certify the position that constraint review of the legal framework is not an effective strategy as far as the implementation of the national policy on the identification system in Nigeria is concerned.

Upgrade of existing ICT facilities in identity-related agencies was earmarked as a formidable strategy in the policy document. The result from the field survey indicated that this was a less effective strategy. This result was supported by $78.6 \%$ of the sampled staff. The provision of the user-friendly pre-enrolment electronic interface was established as an extremely effective strategy that aided the implementation process of the policy. $57.1 \%$ of the respondents placed pre-enrolment electronic interface as an extremely effective strategy. Therefore, the pre-enrollment site created by the agency considerably aided the implementation process of the policy.

Also, the pre-field survey indicated that the agency-branded the creation of mobile registration centres as another strategy that was expected to deepen the implementation process of the policy. After testing this as a variable, the result negated the variable as an effective strategy being employed by the Commission. The result shows that as much as $67.9 \%$ of the respondents considered mobile registration centres to be a less effective strategy. The inter-agencies collaboration was tested among the staff as a strategy employed in implementing the policy. The outcome of the survey revealed that collaboration among relevant government agencies is an effective strategy in the implementation process. This position was upheld by $57.1 \%$ of the respondents. This indicated that inter-agencies collaboration positively influenced the implementation process of the policy.

The electronic messaging platform was tested among the staff as a strategy adopted by the implementing agencies. The result of the analysis depicted that electronic messaging has been less effective as a strategy. This assertion was premised on the opinion of $71.4 \%$ of the respondents. This result is an indication that electronic messaging deployed by the agency (NIMC) has not been effective. Public awareness and sensitisation programmes were considered to be fairly effective by $25 \%$ and less effective by $60.75 \%$ of the respondents. Here, the study concluded that public awareness and sensitisation programmes of the National Identity Management Commission need to be strengthened since the current awareness programmes appear to be less effective.

To complement results gathered from the respondents through questionnaire administration, qualitative responses were narrated and conclusions were inferred therefrom. Series of questions were posted to the selected interviewees on the strategies adopted in the implementation of the policy. Here, principal officers from NIMC constituted the entire participants in the interview. They included a Deputy Coordinator (Oyo State), one Facility Manager (Oyo State), one enrollment officer (Ekiti State), and two enrollment officers (Ogun State). The majority of the interviewees had been with the Commission for more than five years, this gave room for more questions to be posed as it was expected that they were familiar with the activities and workings of the Commission. The researcher further requested the participants to describe the implementation strategies of the agency. Their responses raised some positive points as well as some negative points. In the area of financial arrangement, a vast number of responses gathered from respondents indicated that the public-private partnership listed as a strategy in the policy document did not enjoy adequate attention from the government. For instance, a deputy coordinator remarked that:

at the inception of the agency private initiatives and finance arrangements were given chance. Unfortunately, something went wrong with the arrangement. Private partners 
systematically withdrew by not honouring their obligations toward the agreement with the government

Similarly, harmonisation and integration timelines according to the majority of interviewees had not been optimally followed by the stakeholders in the identity industry in Nigeria. A field officer who pleaded anonymity veraciously indicted government monitoring and enforcement effort. He said, "as we speak, more than five governmental agencies still engage in capturing of biometrics as against the policy and the Act that established NIMC, we still operate a fragmented system of identification".

A good number of the interviewees across the study locations scored the deployment of the pre-enrollment interface on the Commission website as an efficient strategy that came with the policy implementation. A manager from NIMC's state office in Ekiti State affirmed that "with the pre-enrollment platform, the number of queues witnessed by the Commission has reduced to a considerable extent".

During an extensive interview session with one of the participants, the motivation of employees was highlighted and rated very low. Although the motivation of employees as an implementation strategy of the policy was not raised in the research instrument, it came up. His comment emotionally captured the issue of motivation when he pointed out that:

The motivation strategy of the commission is not felt by the workers on the field. For instance, in our office we have issues with the printer, so we have to go Abeokuta on weekly basis to print the registration slip of which no provision was made for transport either in kind or cash. Another is the issue of contract staff who are not paid in consonance with what other federal workers get. All these will not allow the implementation to run smoothly. Something must be done.

The interviewer specifically demanded the opinion of some of the interviewees on the deployment of mobile enrollment centres as a strategy that will enrol more Nigerians. It appears that mobile strategy was just a dream that did not come to reality. This assertion draws it back from the responses of some interviewees which suggested that truly the government (i.e. NIMC) nursed the idea of mobile enrollment centres but the idea was not given much backing. The researcher also queried the interviewees on whether any collaboration between NIMC and other government agencies toward implementation of the policy existed. From the narratives of the interviewees, collaboration among government agencies has not been optimally utilised. Two issues came up during the interview, one was the use of the national identification number (NIN) as a pre-requisite document for filling or enrolling on the database of other identity-related agencies. Qualitative responses suggested that this window of collaboration to creating a unique identification system in Nigeria was not embraced by sister agencies. The other issue was the establishment of desk offices of all other agencies that deal with identity-related information. This also was not being implemented according to the responses gathered from the interview conducted. This implies that collaboration between NIMC and other agencies did not yield any meaningful result as an implementation strategy. 
Table 1. Implementation strategies adopted for the identification policy $(\mathrm{N}=28)$

\begin{tabular}{|c|c|c|c|c|c|c|c|}
\hline \multirow[b]{2}{*}{$\mathrm{SN}$} & \multirow[b]{2}{*}{ Variables } & $\mathrm{EE}$ & E & FE & LE & NY & \multirow{2}{*}{$\begin{array}{c}\sum \\
(\%)\end{array}$} \\
\hline & & $\begin{array}{c}\mathrm{f} \\
(\%)\end{array}$ & $\begin{array}{c}\mathrm{F} \\
(\%)\end{array}$ & $\begin{array}{c}\mathrm{f} \\
(\%)\end{array}$ & $\begin{array}{c}\mathrm{F} \\
(\%)\end{array}$ & $\begin{array}{c}\mathrm{f} \\
(\%)\end{array}$ & \\
\hline 1 & $\begin{array}{l}\text { Adoption of public-private partnership in the } \\
\text { provision of appropriate technology and e-identity } \\
\text { solutions. }\end{array}$ & $\begin{array}{c}1 \\
(3.6)\end{array}$ & $\begin{array}{c}2 \\
(7.1)\end{array}$ & $\begin{array}{c}6 \\
(21.4)\end{array}$ & $\begin{array}{c}17 \\
(60.7)\end{array}$ & $\begin{array}{c}2 \\
(7.1)\end{array}$ & $\begin{array}{c}28 \\
(100.0)\end{array}$ \\
\hline 2 & $\begin{array}{l}\text { Adoption of harmonisation timeline for integrating } \\
\text { existing civic registrations in the new database. }\end{array}$ & - & $\begin{array}{c}3 \\
(10.7)\end{array}$ & $\begin{array}{c}18 \\
(64.3)\end{array}$ & $\begin{array}{c}7 \\
(25.0)\end{array}$ & - & $\begin{array}{c}28 \\
(100.0) \\
\end{array}$ \\
\hline 3 & $\begin{array}{l}\text { Deployment of national ICT infrastructure that drives } \\
\text { implementation process. }\end{array}$ & $\begin{array}{c}5 \\
(17.9) \\
\end{array}$ & $\begin{array}{c}7 \\
(25.0) \\
\end{array}$ & $\begin{array}{c}14 \\
(50.0) \\
\end{array}$ & $\begin{array}{c}2 \\
(7.1) \\
\end{array}$ & - & $\begin{array}{c}28 \\
(100.0) \\
\end{array}$ \\
\hline 4 & $\begin{array}{l}\text { Constant review of the legal framework necessary for } \\
\text { installing an identification system. }\end{array}$ & - & $\begin{array}{c}1 \\
(3.6) \\
\end{array}$ & $\begin{array}{c}7 \\
(25.0) \\
\end{array}$ & $\begin{array}{c}2 \\
(3.6) \\
\end{array}$ & $\begin{array}{c}18 \\
64.3 \\
\end{array}$ & $\begin{array}{c}28 \\
(100.0) \\
\end{array}$ \\
\hline 5 & $\begin{array}{l}\text { Upgrade of existing ICT infrastructure facilities } \\
\text { installed in the relevant government agencies. }\end{array}$ & - & $\begin{array}{c}3 \\
(10.7) \\
\end{array}$ & $\begin{array}{c}2 \\
(7.1) \\
\end{array}$ & $\begin{array}{c}22 \\
(78.6)\end{array}$ & $\begin{array}{c}1 \\
(3.6) \\
\end{array}$ & $\begin{array}{c}28 \\
(100.0) \\
\end{array}$ \\
\hline 6 & $\begin{array}{l}\text { Provision of user-friendly pre-enrollment electronic } \\
\text { interface }\end{array}$ & $\begin{array}{c}16 \\
(57.1) \\
\end{array}$ & $\begin{array}{c}4 \\
(14.3) \\
\end{array}$ & $\begin{array}{c}6 \\
(21.4) \\
\end{array}$ & $\begin{array}{c}2 \\
(7.1) \\
\end{array}$ & - & $\begin{array}{c}28 \\
(100.0) \\
\end{array}$ \\
\hline 7 & Deployment of mobile registration centre. & $\begin{array}{c}2 \\
(7.1) \\
\end{array}$ & $\begin{array}{c}4 \\
(14.3) \\
\end{array}$ & $\begin{array}{c}2 \\
(7.1) \\
\end{array}$ & $\begin{array}{c}19 \\
(67.9) \\
\end{array}$ & $\begin{array}{c}1 \\
(3.6) \\
\end{array}$ & $\begin{array}{c}28 \\
(100.0) \\
\end{array}$ \\
\hline 8 & $\begin{array}{l}\text { Promotion of inter-agencies collaboration among } \\
\text { relevant MDAs. }\end{array}$ & $\begin{array}{c}2 \\
(7.1) \\
\end{array}$ & $\begin{array}{c}16 \\
(57.1)\end{array}$ & $\begin{array}{c}5 \\
(17.9) \\
\end{array}$ & $\begin{array}{c}3 \\
(10.7)\end{array}$ & $\begin{array}{c}2 \\
(7.1)\end{array}$ & $\begin{array}{c}28 \\
(100.0)\end{array}$ \\
\hline 9 & Deployment of electronic messaging platform & $\begin{array}{c}1 \\
(3.6)\end{array}$ & $\begin{array}{c}3 \\
(10.7) \\
\end{array}$ & $\begin{array}{c}1 \\
(3.6)\end{array}$ & $\begin{array}{c}20 \\
(71.4)\end{array}$ & $\begin{array}{c}3 \\
(10.7) \\
\end{array}$ & $\begin{array}{c}28 \\
(100.0)\end{array}$ \\
\hline 10 & $\begin{array}{l}\text { Organising public awareness and sanitisation } \\
\text { programmes for members of the public. }\end{array}$ & - & $\begin{array}{c}2 \\
(7.1)\end{array}$ & $\begin{array}{c}7 \\
(25.0)\end{array}$ & $\begin{array}{c}17 \\
(60.7)\end{array}$ & $\begin{array}{c}2 \\
(7.1)\end{array}$ & $\begin{array}{c}28 \\
(100.0)\end{array}$ \\
\hline
\end{tabular}

Source: Field Survey, 2018.

NB: Extremely Effective (EE); Effective (E); Fairly Effective (FE); Less Effective (LE); Not Yet (NY); Total ( $($ )

\section{Result Analysis}

On the implementation strategies adopted for the study, it was established by $60.7 \%$ of the respondents that the use of public-private partnerships as a strategy was not effective. This position enjoyed the support from the responses provided by the interview. Supporting evidence shows that public-private partnership was initially involved in the implementation phases of the policy but due to financial constraints of both the government and the private partners, PPP as an implementation strategy was relegated. This finding supports the view of Anderson et al (2016) where he noted that the two consortia, Chams and Onesecure Card who signed an agreement with the government to provide infrastructure and facilities on a public-private partnership arrangement failed due to insufficient funds to fulfil their mandate.

The harmonisation timeline was considered fairly useful in the process of implementing the policy $(64.3 \%)$. This result was negated from the views expressed in the interview conducted. The argument was that stakeholders in the identity industries in Nigeria have not optimally followed the implementation timeline especially in the area of harmonisation of existing functional databases. This finding derived literature support from International Bank Reconstruction Development (2016) and Aliyu (2017). The two studies confirmed the existence of a fragmented identity landscape in Nigeria. This finding cast doubt on the policy objective of ensuring interoperability among government agencies.

Still, on the strategies adopted for the implementation of national policy on identity management system, the result showed that mobile registration centres had not been explored by the agency implementing the policy. 
Responses from the interview confirmed that the mobile registration centre was indeed employed as a strategy to expand the scope of enrollment but this was without much backing from the government. This result indicated that the use of mobile registration platform has not been fully explored unlike what is obtainable in Pakistan where Van and motorcycle units were deployed as mobile registration centres for educating and enrolling citizens in rural areas (Malik, 2014). The inter-agencies collaboration was reported to be effective by the respondent's but evidence gathered through the interview revealed that inter-agencies collaboration as a strategy was not effective. This finding is not unconnected to the fragmented nature of the identity management system in Nigeria as reported by Aliyu (2017). Udunze (2014) also identified a lack of collaboration among government agencies. He supported his view with the premise that NIMC contested the legal right of the Bank Verification Number (BVN) programme by Nigerian banks, a public act that falls under the exclusive jurisdiction of the NIMC. Similarly, the electronic messaging platform was not as effective as expected. This finding was supported by $71.4 \%$ of the respondents, this is similar to submissions generated through interviews. The use of the electronic messaging platform was deployed to fast track the implementation process of the policy (Aliyu, 2017). Electronic messaging was employed to enhance the enrollment process as well as fast track collection of the new identity smart card.

\section{Conclusion and Recommendations}

The study discovered that most of the existing implementation strategies employed for the new Identification Policy in Nigeria have not been quite effective. This is apparent in the deviation between the policy targets and the policy outcomes. Hence, the need for the relevant agency to review the policy strategies as the implementation process is ongoing to fast-track and close the existing lags in the policy targets. By so doing, the under listed steps are suggested.

i. The enrollment process should be decentralised to ease the burden of congestion during enrollment as well as fast track enrollment rates among eligible enrollees. This could be done using the model adopted in the telecommunication industry, where registered private individuals are permitted to capture biometric data of the sim cardholder. This will make enrollment to be more accessible and affordable to the public.

ii. A working public-private partnership model should be designed to drive the implementation of the policy to provide alternative sources of finance as well as promote a self-sustaining identity system in Nigeria. This arrangement should ensure production and distribution of the Multipurpose Smart Card after two weeks of receiving identification number to further deepen public trust in the new identity regime being put in place by the policy as delay in the production of these cards undermines public interest in the entire process.

iii. Mobile enrollment centres should be deployed by the Commission to provide reliable means to enrol the vulnerable such as rural dwellers, physically challenge and the poor into the database.

\section{References}

Aliyu, A. A. (2017). Overcoming Data Integration Challenges. Abuja, Nigeria: National Identity Management Commission.

Anderson, C., Biscaye, P., Coney, S., Ho, E., Hutchinson, B., Neidhartdt, M., \& Reynolds, T. (2016). ICT Facts and Figures. International Telecommunications Union.

Asian Development Bank. (2016). Identity for Development for Asian and the Pacific. Mandaluyong City, Philippines.

Ayamba, I. A., \& Ekanem, O. (2016). National Identity Management in Nigeria: Policy Dimensions and Implementation. International Journal for Humanities and Social Science Studies, 3(1), 279-287.

Chakrabarty, N. K. (2012). UID (Aadhaar) - Its effect on financial inclusion. The Management Accountant, $47(1), 35-3$.

Dreze, J. (2010, November 25). Unique facility or recipe for trouble. The Hindu.

Gerdeman, D. (2012). India's ambitious National Identification Program. Harvard Business School, Working Knowledge, 1-2. Retrieved from http://hbswk.hbs.edu/item/6957.html

Greenwood, D. (2007). The context for Identity Management Architectures and Trust Models. Paper presented at the OECD Workshop on Digital Identity Management, Trondheim.

Hansen, M., Krasemamn, H., Krause, C., Rost, M., \& Genghini, R. (2003). Identity Management Systems (IMS): 
Identification and Comparison. Technical Report, Independent Centre for Privacy Protection (ICPP), Kiel (Germany). Study made for the Institute for Prospective Technological Studies - Joint Research Centre Seville (Spain). $\quad$ Retrieved September 27, 2012, from http://www.datenschutzzentrum.de/idmanage/study/ICPP_SNG_IMS_Study.pdf

Kant, C., \& Sharma, Y. (2013). Enhanced Security Architecture for Cloud Data Security. International Journal of Advanced Research in Computer Science and Software Engineering, 3(5), 570-575.

Kaushik, M. (2010). Configuring the UID. Business Today, 19(22), 12.

Liberty Alliance Project. (2004). Whitepaper: Benefits of Federated Identity to Government.

Lips, M., \& Pang, C. (2008). Identity Management in Information Age Government Exploring Concepts, Definitions, Approaches and Solutions. Victoria University of Wellington, Kelburn, New Zealand.

Malik, T. (2014). Technology in the Service of Development: The NADRA Story. Retrieved from http://www.cgdev.org/publication/technology-servicedevelopment

Mukherjee, A., \& Nayar, L. (2011, December 5). Aadhar-A few basic issues. Outlook India.

Musa, Y. (2000, October 13). Nigeria: ID Cards May Control Rigging. Weekly Trust, pp. 10.

National Identity Management Commission. (2013). Harmonization and Integration Policy. Retrieved May 7 , 2016, from www.nimc.gov.ng

National Identity: NIMC captured 14 million Nigerians by 2016. (2017, February 17). Technology Time. https://doi.org/10.1016/S1350-4789(16)30303-8

National ID-NIMC 'captured 14 million Nigerians' by 2016. (2017, February). Big Story. Retrieved from technology times.ng/nimc-captures-14-million-Nigerians-national-id

OECD. (2007). OECD Recommendation on Electronic Authentication and OECD Guidelines for Electronic Authentication. Retrieved from www.oecd.org/dataoecd/32/45/38921342.pdf

OECD. (2011). National Strategies and Policies for Digital Identity Management in OECD Countries. OECD Digital Economy Papers, No. 177.

Organisation for Economic Cooperation Development Report. (2011). Digital Identity Management: Enabling Innovation and Trust in the Internet Economy.

Oxford Internet Institute. (2007). E-Infrastructures for Identity Management and Data Sharing: Perspectives across the Public Sector: Oxford Internet Institute.

Pati, R. K., Kumar, V., \& Jain, N. (2015). Analysis of Aadhaar: A Project Management Perspective. IIM Kozhikode Society \& Management Review, 4(2), 124-135. https://doi.org/10.1177/2277975215610687

Peshwani, P., \& Joshi, B. (2016, October 26). Aadhaar - Identification Simplified, Myths Busted. The Wire.

Peshwani, P., \& Joshi, B. (2016, October 26). Aadhaar - Identification Simplified, Myths Busted. The Wire.

Ramanathan, U. (2010). The personal is personal. The Indian Express, International Environmental Law Research Centre. Retrieved from http://www.ielrc.org/content/n1002.Pdf.

Udunze, B. (2014). \$55m biometric budget: CBN, NIMC at war over control of BVN scheme. The Sun. Retrieved

from http://sunnewsonline.com/new/55m-biometricbudget-cbn-nimc-atwar-over-control-of-bvn-scheme/

World Bank. Identification for Development: Nigeria. Conference Report. (2015). Washington. Retrieved from https://openknowledge.worldbank.org/handle/10986/26437

\section{Copyrights}

Copyright for this article is retained by the author(s), with first publication rights granted to the journal.

This is an open-access article distributed under the terms and conditions of the Creative Commons Attribution license (http://creativecommons.org/licenses/by/4.0/). 